\title{
Ranking of Factors Influencing Cost Overrun and Project Delay of Repetitive Building Construction Project in Nigeria
}

\author{
Dorcas Bamitale Oluyemi-Ayibiowu ${ }^{1}$, Emmanuel Kayode Falola ${ }^{2}$ \\ ${ }^{1,2}$ Department of Civil Engineering, Federal University of Technology, Akure, Ondo State, Nigeria
}

\begin{abstract}
The high rate and cost of construction project abandonment in Nigeria had led researchers into developing various options for efficient project delivery. To achieve that, a thorough knowledge of the project efficiency influencing factors is required. A questionnaire survey was conducted among one hundred and forty-one (141) participants across three states in Nigeria. Sixty-three (63) risks that occur on an estate construction project site was grouped into seven (7) constraints, and each participant were asked to rate the effect of theserisks separately on their severity to leading to project cost overrun and delayed completion time through a 5-point Linkert scale ranging from Strongly influence to Virtually no influence. The Friedman analysis result showed Productivity constraint as the most influential constraint with mean significance score of 4.89 followed by the resource constraint with score of 4.85 for cost overrun. This showed that the productivity of the resource crew is the most significant factor in preventing cost overrun. Statistical ranking result also showed productivity and precedence constraint as the most influential factor of project delay. This highlighted the importance of an effective schedule plan to repetitive construction as it prevents resource interruptions without limiting its productivity.
\end{abstract}

Keywords: Project Time Delay, Cost overrun, Ranking, Repetitive Construction, Building

\section{INTRODUCTION}

A project is a sequence of tasks that must be finished to accomplish a particular outcome or set of results. Projects containing several comparable job units, i.e., units with the same structure of operations but distinct sizes are generally referred to as repetitive projects. Repetitive building projects are quite prevalent in the construction industry and can be split into two classifications which are projects that are repetitive owing to their geometric design and those due to a uniform repetition of a unit job. These projects make up a big part of the construction industry [1].

A growing population is one of the features of a developing country, where Nigeria is the highest in Africa. As a consequence, the housing problem is one of Nigeria top priorities. [2]. However, the government's inability to provide housing / shelter for all its citizens has made private firms and building firms take up the challenge of providing housing facilities for medium and high-income earners in the form of housing and construction of industrial real estate, mostly consisting of repetitive housing units and building operations. However, the failure to finish projects on time and within the budget remains a chronic issue throughout the world and is worsening, especially in Nigeria.[3].

This research set out to investigate the technical factors on a repetitive construction site, of which an estate construction site, was chosen as example, which influences the chance of occurrence of project time delay and cost overruns. This research is expected to aid the project managers in effective and optimal decision makings when faced with these factors during repetitive construction project management.

\section{LITERATURE REVIEW}

A project is a set of activities that must be done in a precise order in order to meet a specific goal within a given timeframe and budget. A project can also be defined as a collection of inputs and outputs necessary to accomplish a specific aim [4]. Projects can be simple or complicated, and they can be handled by one person or multiple people. Project management, on the other hand, is the coordination of a sequence of interconnected tasks that must be completed in order to achieve a given outcome on a specific date, within a budgeted cost, and of acceptable quality. Project planning and scheduling is one of the most important aspects of successful and efficient project management [4].

Repetitive projects are defined as those that comprise multiple identical or comparable units. These projects account for a sizable chunk of the construction sector. The following are some examples of recurring building projects:Vertical structures [such as high-rise buildings, building cores, cooling towers, and other slip or climb form structures, as well as deep shafts], Horizontal [Low-rise structures like portal frame factories and retail malls, as well as technical projects like pipelines, motorways, bridges, and jetties], Combination [Low-rise multi-story building constructions, such as those for hospitals and institutions, as well as coal bunkers, concrete dams, and important plant installations at power plants].

Human resources (crews) are frequently required to perform the same work in various units (locations and segments) of repetitive construction projects by moving from one unit to 
the next. Because of this frequent resource movement, an effective schedule is important to ensure the uninterrupted usage of resources of repetitive activities between units

The private sector plays a major role in National development and are of utmost importance in boosting the economy of the Nation such as Nigeria. The benefits derived by both parties have led to competitions among companies as regards customer satisfaction, which to the construction industry, involves project delivery at minimum cost and time. There have been serious concerns raised concerning construction projects that have not been completed in various parts of the country despite massive cash mobilization. Due to inadequate management approaches, Nigeria has witnessed several failures and project abandonment. Majority of the projects did not finish on time or within budget. Contractors will be expected to deliver the project within a set time and cost based on contract agreements and terms, therefore time is also a prominent element [10]. Nigeria's construction industry faces numerous issues in terms of project management, particularly in terms of time and cost management. Project completion on schedule, on budget, and with the intended quality are basic conditions that are rarely met in the construction sector. This has become a global issue, resulting in project cancellation and significant financial loss.Delays and cost overruns aren't always the product of a single calamity. During the course of project execution, they frequently develop slowly. Delays can cost a business owner a lot of money. The successful completion of building projects, as well as maintaining them within budget and schedule, is dependent on a process that needs solid engineering judgment. [11].There is therefore a need to identify and evaluate the most severe factors influencing project duration and cost overrun.

\section{PREVIOUS RESEARCH ON FACTORS INFLUENCING DELAYS AND COST OVERRUNS ON CONSTRUCTION PROJECT}

There are numerous reasons that lead to building project delays and cost overruns. The degree of these delays and cost overruns varies greatly depending on the type of project and location. Several studies have been conducted around the world to discover the causes of building project delays. Chan and Kumaraswamy [12] performed a survey to establish and rank the relative relevance of the major determinants of building delays. They looked at and ranked the primary elements that affect building time, dividing them into two categories: the role of parties in the local construction sector and the type of projects. Poor site management and supervision, unanticipated ground conditions, low speed of decision making involving all project teams, client induced modifications, and necessary variations of works were the five leading reasons of delays, according to their survey results.
In a comparative study conducted in Egypt, Sweis et al. [13] indicated that the contractor's financial issues and the owner's excessive number of modification orders are the major causes of construction delays.

Tumi et al. [5] investigated the overruns in project cost in Libyan construction projects. They came to the conclusion that faulty planning was the leading cause of construction project cost overruns, followed by a lack of effective communication, material shortages, design flaws, and financial issues. Endut et al. [6] investigated the time and cost performance of 359 projects in Malaysia (301 new constructions and 58 refurbishment projects). There were 301 governmental projects and 51 private enterprises among them. Only 18.2 percent of public sector projects and 29.45 percent of private sector projects had no time deviation (no delays), according to the report, while the average rate of cost overrun for all projects was 49.71 percent.Chan and Kumaraswamy [7] performed a survey to establish and rank the relative relevance of the major determinants of building delays. They looked at and ranked the primary elements that affect building time, dividing them into two categories: the role of parties in the local construction sector and the type of projects. Poor site management and supervision, unanticipated ground conditions, low speed of decision making involving all project teams, client induced modifications, and necessary variations of works were the five leading reasons of delays, according to their survey results. According to Omoregie and Radford [8], the minimum average percentage escalation in costs of projects in Nigeria is $18.8 \%$.In Nigeria, Amu and Adesanya [9] looked into 3,407 projects, just 24 of which were completed on schedule, 1517 were delayed, and 1812 were abandoned.

However, very few researches looked into the factors affecting project delay and cost overruns based on project type uniqueness, especially repetitive construction project, in which this study was based on by investigating that of Nigeria Construction Industry

\section{METHODOLOGY}

\section{A. Research Study Area}

Three locations (study areas) were selected in Nigeria for this research. These are Abuja, Lagos and Port Harcourt. The choices were based on commercial viability, level of urbanization and more importantly population to land ratio (i.e., high number of populations to scarce available land).Fig.1 shows the map of Nigeria highlighting the three regions used as the study area 
Fig. 1: Map of Nigeria Showing the Study Areas

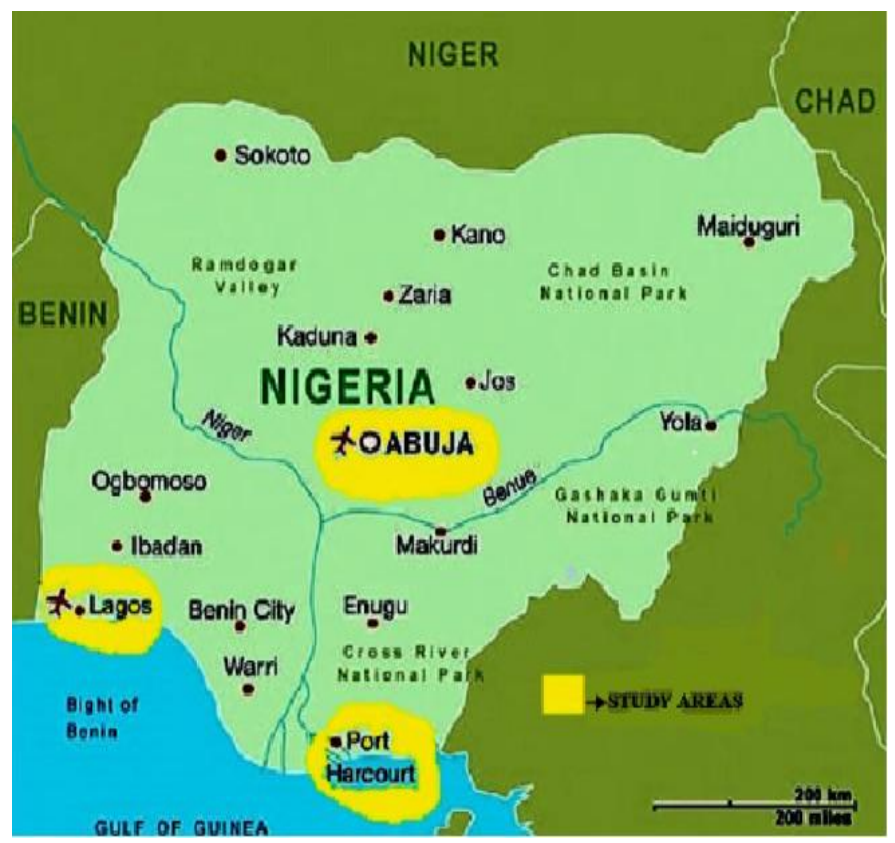

In each of the case study areas, a large housing estate construction project-site was selected for collecting data as regards their responses to the effect of the various constraintsbased decision on the project cost and time. However, the site used for this research was chosen based on fulfilment of certain conditions which were:

- The construction site must contain several identical or similar units of construction work as in an estate building construction site.

- The construction work must be massive with wide use of human and material resources.

- The individual construction work should be carried out using similar methods of material and mechanical plants.

\section{B Population and Sample Size}

Clients, contractors, consultants, project managers, site engineers, and subcontractors make up the Nigeria construction industry's population. Because it is impossible to test everyone in the population, it is critical to select a representative sample. Simple random sampling (SRS) was used to calculate the total population size $(\mathrm{N})$ and questionnaire sample size (n) for this study. All registered building construction sector workers, as well as current construction sites in the study locations, were included in the study population. Contractors, subcontractors, project managers, and site engineers were among the people who received questionnaires. As of the time of this study, the total population size $(\mathrm{N})$ was 350 building projects were ongoing. Population size (N) chosen in Lagos, Abuja and Port Harcourt was 200, 50 and 100 respectively. The following equation was used to compute the sample size for the questionnaire;

$$
\mathrm{n}=n^{!} /\left[1+\left(n^{!} / N\right)\right]
$$

where

$$
\begin{aligned}
& \mathrm{N}=\text { total number of populations } \\
& \mathrm{n}=\text { sample size from finite population } \\
& \mathrm{n} !=\text { sample size of infinite population }=S^{2} / V^{2}
\end{aligned}
$$

where:

$$
\begin{aligned}
& S^{2}=\text { the variance of the population elements } \\
& V^{2}=\text { Standard error of sampling population. [14] }
\end{aligned}
$$

From a population size of 200, 100 and 50 for Lagos, Porth Harcourt and Abuja respectively, the calculated sample size (n) was 54, 50 and 37 for Lagos, Porth Harcourt and Abuja respectively, making a total of one hundred and fourty-one (141) questionnaire that was administered for the given population size.

\section{Questionnaire Development}

Supplementary data was collected via a questionnaire. There are two (2) sections to the questionnaire. The demographic part, which contained the information provided by the respondents, and the respondent analysis portion, which comprised the responses provided by the respondents. A total of eight (8) restrictions were defined in the beginning, all of which occur on a regular basis in construction projects. Each limitation is surrounded by nine (9) different cases/circumstances, for a total of seventy-two (72) cases/scenarios. The final questions created after the pilot research to validate the content, however, had seven (7) limitations and sixty-three (63) cases/scenarios. Each respondent was then asked to rate the negative impact of such situations on project time and expense on a five-point scale known as the Linkert scalewhich were

- $\quad$ Strongly Influence - 5

- $\quad$ Little Influence -4

- May or May not Influence- 3

- $\quad$ No influence -2

- Virtually no Influence -1

The number represents the weights given to each decision. These weights were used in the corresponding analysis that followed. A total of one hundred and forty-one (141) questionnaires were distributed to randomly selected respondents (contractors, consultants, site engineer, project managers, sub-contractors and client). The questionnaires were then recovered and analysis were carried 


\section{Relative Importance Index Analysis:}

The Relative Importance Index method (RII) was used to determine the Respondents' perception of the relative importance of the effect of the given risks on project cost and time. The relative importance index (RII) was calculated as follows:

$$
\begin{aligned}
& \text { Relative Important Index (R. I. I) } \\
& \qquad=\frac{5_{n_{5}}+4_{n_{4}}+3_{n_{3}}+2_{n_{2}}+1_{n_{1}}}{5 \mathrm{~N}}
\end{aligned}
$$

for $(0 \leq$ R.I.I $\leq 1)$

\begin{tabular}{|c|c|c|}
\hline & $\mathrm{n}_{5}$ & is Number of Respondent for strongly influence \\
\hline & $\mathrm{n}_{4}$ & is Number of Respondent for little influence \\
\hline & $\mathrm{n}_{3}$ & is Number of Respondent for May or May no \\
\hline & $\mathrm{n}_{2}$ & is Number of Respondent for No influence. \\
\hline & $\mathrm{n}_{1}$ & is Number of Respondent for Virtually no influence. \\
\hline & $\mathrm{N}$ & is Total number of Respondent. \\
\hline
\end{tabular}

where:

The constraints with the highest RII value was ranked first (1), the next two (2) and so on. Interpretation of the RII values is as follows:

$$
\begin{aligned}
& \text { RII }<0.60, \text { items is assessed to have low rating } \\
& 0.60 \leq \mathrm{RII}<0.80 \text {, item assessed to have high rating } \\
& \mathrm{RII} \geq 0.80, \text { item assessed to have very high rating. }
\end{aligned}
$$

The Severity Index (I) was also calculated to interpret the degree of influence of the effect of the various cases/scenarios to leading to project cost overrun and time delay, if not properly handled. It is calculated as R.I.I x 100.

\section{E Friedman Analysis:}

The Friedman test is a non-parametric alternative to the repeated measurements one-way ANOVA. It, like ANOVA, uses mean rank to show how a group of independent variables statistically differ from one another. When the parameter being assessed is ordinal, as it is in this study, it is employed to test for differences across groups. The Friedman test, on the other hand, not only demonstrated that there is a statistical difference between parameters by obtaining the average mean index values for the ordinal data groups, but it also ranked them according to their level of importance using weights assigned to the ordinal variables that make up the data, in this case, the Linkert scale responses. The test was carried out in addition to the examination of the Relative Importance Index. Its outcome was compared to that of the Relative Important Analysis Test, and a conclusion was reached as a result.

\section{RESULT AND DISCUSSION}

A total of one hundred and forty-one (141) questionnaires were administered to randomly selected participants across three study areas (Abuja, Lagos and Porth-harcourt) within Nigeria. A total of one hundred and thirty (130) responses were collected, evaluated and analyzed, representing $92.19 \%$ respondent rate for the research. As shown in Table 1, out of the one hundred and thirty (130) questionnaires that was analyzed, fifty (50) of the respondents were from Lagos

Table 1: Questionnaire distributed and responses

\begin{tabular}{|c|c|c|c|c|}
\hline & Abuja & Lagos & $\begin{array}{c}\text { Porth- } \\
\text { Harcourt }\end{array}$ & Total \\
\hline $\begin{array}{c}\text { Number } \\
\text { Distributed }\end{array}$ & 37 & 54 & 50 & 141 \\
\hline $\begin{array}{c}\text { Number of } \\
\text { Responses }\end{array}$ & 34 & 50 & 46 & 130 \\
\hline $\begin{array}{c}\text { Percentage of } \\
\text { Responses }\end{array}$ & 91.89 & 92.59 & 92 & 92.19 \\
\hline \multicolumn{7}{|c|}{$\%$ Responses = (Number of responses/Number Distributed) x 100\% } \\
\hline
\end{tabular}

\section{A Identification Of Constraints Inluencing Project Delay And Cost Overrun}

Sixty-three (63) problematic scenarios that occur on repetitive construction project site was identified from literature review. The 63 scenarios were grouped into seven (7) major constraint with each one of the sixty-three scenarios belonging to a particular constraint, with each constraint given an identifier.The constraint groups include Resource, Precedence, Productivity, Quantity of work, Options, Project Environment and Price fluctuation constraints.

\section{Brelative Importance Index Result (Cost Overrun)}

Figure 2 showed the ranking pattern and relationshipbetween the sixty-three (63) cases for cost overruns responses. The ranking pattern and relationship, from the relative importance index result.

From Fig.2, The Resource constraint was ranked highest, followed by Productivity constraint and the Quantity of work constraint. For the first ten (10) ranks, the quantity of work, the resource and the productivity constraint were both ranked thrice. This showed the level of importance they play to the safe cost delivery of a repetitive construction project, especially the estate construction site. This means that, the Productivity, which is a function, of the resource and the volume of works are crucial, and should be maximized objectively to get the effective profit returns on the project.

The last twenty ranks (i.e., 40 to 63 ) were populated by the Options constraint, the Project Environment constraint and the price fluctuation constraint. Options and Project Environment were both ranked least, having six (6) clusters each at the 4060 region and none at the 1-20 ranked region. This was followed by the Price fluctuation constraint having 4 clusters at the least 40-60 region but an appreciable quantity spread out at the mid-section (i.e., 20-40 region) of the graph. 
However, much more spread, at the mid-rank, is the Precedence constraint. Precedence constraint was borne out of the activity time relationship of a repetitive construction project. This showed that its effect is closely linked to and are therefore majorly affected by the other constraints especially by the first three (i.e. Resource, Productivity and Quantity of work). This result was in synchronization with the strong correlation strength Precedence constraint showed with the three afore-mentioned constraint at the inter-matrix correlation resulttable for cost overrun.

\section{Crelative Importance Index Result (Project Delay)}

Figure 3 showed the ranking pattern and relationshipbetween the sixty-three (63) cases for project delay responses. The ranking pattern and relationship, from the relative importance index result.
From Figure 2, Productivity constraint was ranked first, closely followed by the Precedence constraint. The two constraints both made up the clusters for the first 10 ranks. They were highly ranked and regarded as very important to preventing project delay. These two constraints also had equal number of clusters ( 4 each) between them, for the first 10 ranks. They were followed by the Resource constraint and the Quantity of work constraint. The two constraints significantly occupy the mid-part of the chart (i.e., 20 to 40).

The last twenty ranks (i.e., 40 to 63) were populated by the Project Environment constraint and the Option constraint, with the Project Environment ranked least due to its large representation at the lowest side of the rank (i.e. 50 to 63). This was followed by the Price fluctuation constraint having clusters at the least 40-60 region and minimal quantity at the mid-section (i.e. 20-40 region) of the graph.

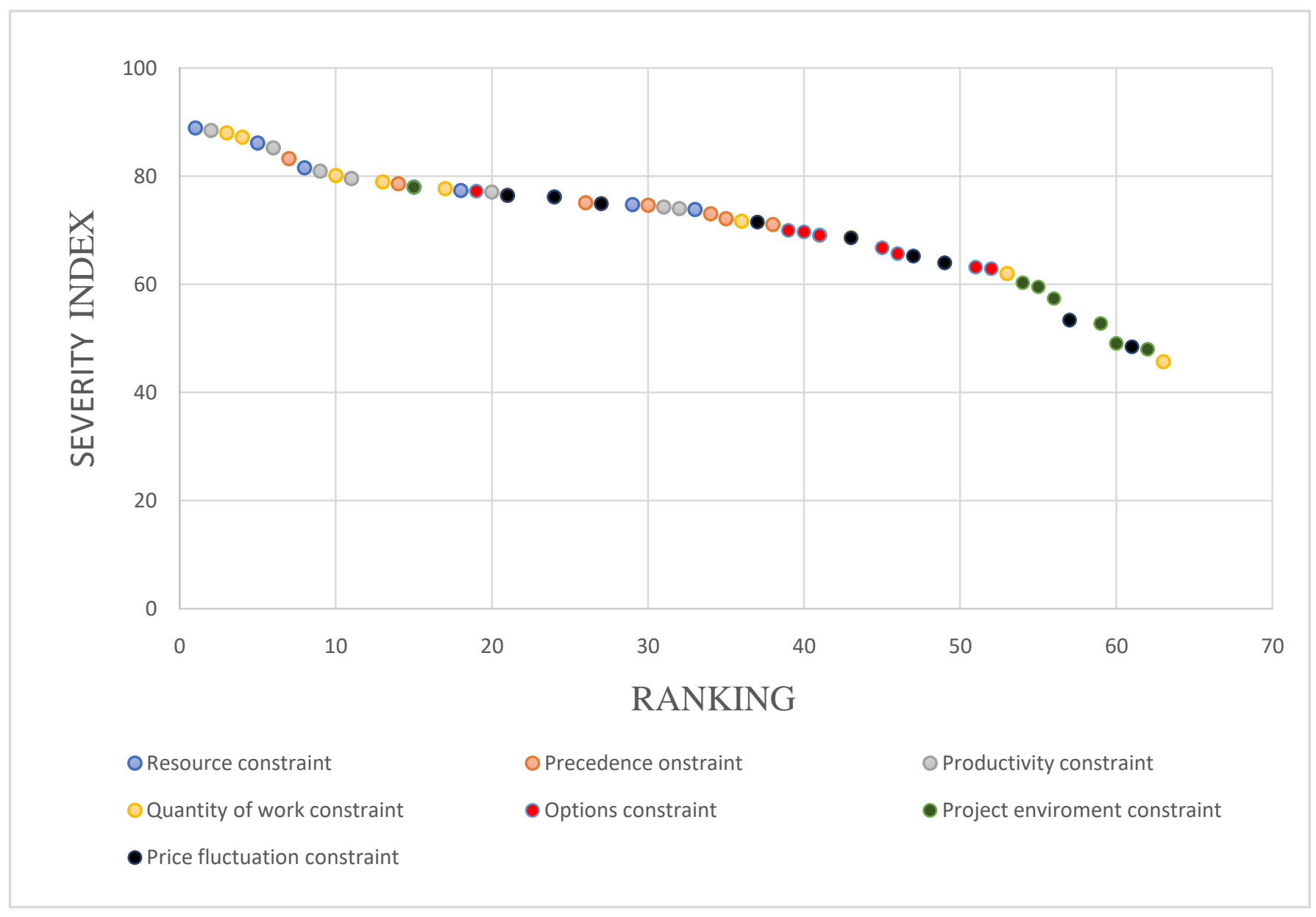

Fig.2: Scatter Chart showing the Constraints Rankings based on the Respondents' Responses for Cost overrun 


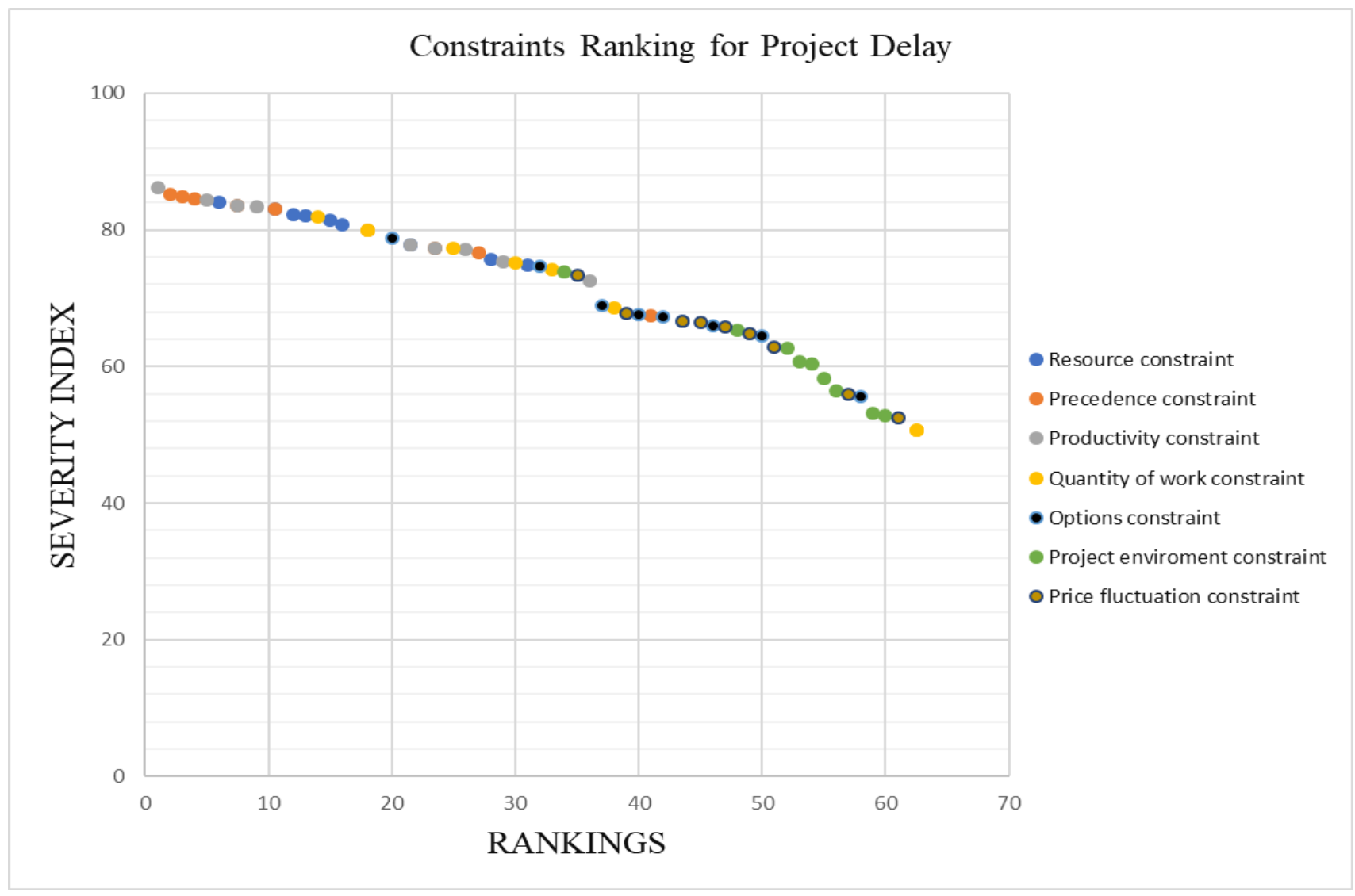

Fig.3: Scatter Chart showing the Constraints Rankings based on the Respondents' Responses for Project Delay

\section{Friedman Analysis Result (Project Delay)}

Friedman is an option for ordinal data to One-way Anova. By calculating its mean index score, it ranks. Table 2 showed the results of the Friedman's evaluation of project delay responses

Table. 2: Friedman's Test Result for Project Delay responses

\begin{tabular}{|c|c|}
\hline Constraints & Rank \\
\hline Productivity constraint & 5.31 \\
\hline Precedence constraint & 5.22 \\
\hline Resource constraint & 5.10 \\
\hline Quantity of work constraint & 3.74 \\
\hline Options constraint & 3.27 \\
\hline Price fluctuation constraint. & 2.87 \\
\hline Project Environment constraint & 2.50 \\
\hline
\end{tabular}

From Table.2, the highest ranked constraint was productivity constraint, closely followed by the Precedence constraint. This result was similar to that obtained from the Scatter plots for the Relative important index ranking. The least ranked constraint was the Project Environment constraint, similar to that obtained from the Scatter plots for the Relative important index ranking for. Resource constraint and Quantity of work constraint followed after the precedence constraint, which was similar to that obtained from the Scatter plots for the Relative important index ranking for Project delay. However, there was a difference, at the other side as Price fluctuation constraint followed after the Project Environment constraint, unlike, in the Scatter plots for the Relative important index ranking for Project delay, where options constrained followed after the Project environment constraint. This is within a permissible error limit and does not render the ranking results inadmissible.

\section{F. Friedman Analysis Result (Cost Overrun)}

Table 3 showed the Friedman's analysis result for the responses on cost overrun

Table 3: Friedman's Test Result for Cost overrun responses

\begin{tabular}{|c|c|}
\hline Constraints & Rank \\
\hline Productivity constraint & 4.89 \\
\hline Resource constraint & 4.85 \\
\hline Quantity of work constraint & 4.62 \\
\hline
\end{tabular}




\begin{tabular}{|c|c|}
\hline Precedence constraint & 4.40 \\
\hline Price fluctuation constraint & 3.48 \\
\hline Options constraint & 3.21 \\
\hline $\begin{array}{c}\text { Project Environment } \\
\text { constraint }\end{array}$ & 2.54 \\
\hline
\end{tabular}

From table 3, Productivity was given the highest rank with 4.89 mean, while the Project Environment constraint was ranked the least with 2.54 mean. This result corroborated with that gotten from the Relative Importance Analysis Scatter chart result. The arrangement also corroborated with the result from the Scatter chart analysis for cost overrun. Productivity and Resource had very close mean scores, they were also close, having same clusters for the first 10 ranks of the scatter diagram. The same also applied to the Price fluctuation and Options constraint.

\section{CONCLUSION}

The most severe constraint influencing project delay in a repetitive construction project were Productivity constraint, Precedence constraint, Resource constraint, Quantity of work constraint, Options constraint, Price fluctuation constraint and Project environment constraint, in that order, with a Friedman's mean significance rank of 5.31, 5.22, 5.10, 3.74, $3.27,2.87$ and 2.50 respectively while that of cost overrun were Productivity constraint, Resource constraint, Quantity of work constraint, Precedence constraint, Price fluctuation constraint, Options constraint and Project environment constraint, in that order, with a Friedman's mean significance rank of 4.89, 4.85, 4.62, 4.40, 3.48, 3.21 and 2.54 respectively. This showed that Productivity is the single most important and influencing factor in a repetitive construction project.

\section{REFERENCES}

[1] Hegazy, T., \& Wassef, N. (2001). Cost optimization in projects with repetitive nonserial activities. Journal of Construction Engineering and Management, vol.127, pp.183-191.
[2] Anyanwu, C. I. (2013). Project Cost Control in the Nigerian Construction Industry. International Journal of Engineering Science Invention, vol.2, pp65-71

[3] Azhar, N.F. (2008) Cost overrun factors in the construction industry in Pakistan. Proceedings: The 1st International Conference on Construction in Developing Countries: Advancing and Integrating Construction Education, Research and Practice. (pp.14-25) Karachi, Pakistan, 18-20 April.

[4] Vanhoucke, M. (2006). Work continuity constraints in project scheduling. Journal of Construction Engineering and Management, vol.132, pp.14-25

[5] Tumi, S.A.H., Omran, A. and Pakir, A.H.K. (2009). 'Causes of delay in Construction Industry in Libya'. Proc. Int. Conf. Administration and Business (pp. 265-272), Univ. Bucharest, Romania, 14-15th November 2009.

[6] Endut, Rohani, I., Akintoye, A. and Kelly, J. (2009). "Cost and time overruns of projects in Malaysia," Proceedings of the $2^{\text {nd }}$ Scottish Conference for Postgraduate Researchers of the Built and Natural Environment (PROBE), Glasgow Caledonian University. Rotterdam (Netherlands), pp. 243-252.

[7] Chan, D.W.M., and Kumaraswamy, M.M. (2002). 'Compressing construction durations: lessons learned from Hong Kong building projects'. International Journal for Project Management. VOL. 20, no.1. pp. 23-35.

[8] Omoregie, A. and Radford, D. (2006). 'Infrastructure Delays and Cost Escalation: Causes and Effects in Nigeria', Paper presented at the Proceeding of sixth international postgraduate research conference.

[9] Amu, O.O. and Adesanya, D.A. (2011). 'Mathematical Expressions for Explaining Project Delays in South western Nigeria', Singapore Journal of Scientific Research; Vol. 1(1), ISSN: 2010-006, Pp.59-67.

[10] Anuja, R. and Parag, M. (2015). Effective Techniques in Cost Optimization of Construction Project, International Journal of Research in Engineering and Technology (IJRET); Volume 04, pp. 46-55.

[11] Le-Hoai, L., Lee, Y.D. and Lee, J.Y. (2008). 'Delay and Cost Overruns in Vietnam Large Construction Projects: A Comparison with Other Selected Countries'. KSCE Journal of Civil Engineering, vol.12, no.6, pp. 367-377.

[12] Chan, D.W.M. and Kumaraswamy, M.M. (2002). Compressing construction durations: lessons learned from Hong Kong building projects. International Journal for Project Management. vol. 20, no.1, pp. 23-35.

[13] Sweis, G., Sweis, R., Abu Hammad, A., and Shboul, A. (2008). Delays inconstruction projects: the case of Jordan. International Journal of Project Management, vol.26, no.6, pp. 665-674.

[14] Mahmoud, M. A. (2012). A Construction Resources Management System for Gaza Strip Contractors'. IJSERT, pp. 100-110 